\title{
LIS Extends to the Research Frontier
}

Advancements in research procedures (research designs and methodologies) and in the development of reliability and validity indicators occur on a cross-disciplinary and interdisciplinary basis. Researchers obviously should monitor these developments and, when appropriate, adapt them to their investigations. However, as Jeffrey N. Gatten indicates in a recent $C \mathcal{E} R L$ article, "a researcher investigating an interdisciplinary phenomenon ... [may approach] the topic from a specific research paradigm rooted in a traditional structure of knowledge. The paradigm may force a particular perspective or approach to conducting research."1

Gatten further observes "that low subject dispersion within the professional literature of library science indicates little effort by librarians at looking towards another discipline... for theory or methodology."2 A number of library science researchers "adopt unsophisticated analytical techniques and utilize limited theoretical frameworks." ${ }^{3}$ They may depend exclusively on a mailed or handdistributed questionnaire and either use descriptive statistics, rather than inferential statistics, or forego any statistical analysis. ${ }^{4}$

Gatten labels library science as an "applied discipline," one that often fails to reference in its literature "relevant research from other disciplines." ${ }^{15}$ The failure of "paradigmatic structures" to "cross the traditional boundaries of established disciplines... [inhibits] interdisciplinary [and cross-disciplinary] research." 6 This editorial does not dispute Gatten's findings, the citation patterns of a number of library and information science (LIS) researchers, or the conclusion that LIS as an "applied discipline appears to be more self-contained" than a "research discipline," such as sociology.

Nonetheless, LIS can draw (and has done so) on procedures and indicators of reliability and validity developed in disciplines such as anthropology, education, management, psychology, public administration, public policy, and sociology. Periodicals, such as Public Opinion Quarterly, and treatises produced by Sage and other publishers present procedural discussions, assessments, and investigations. In fact, guides, such as the Handbook of Research Design and Social Measurement, ${ }^{8}$ offer excellent synopses of procedural alternatives and make it more convenient for neophyte researchers to improve the quality and format of their data collection instruments.

Textbooks, monographs, periodicals, and treatises produced outside LIS apparently infrequently (if at all) reference the procedural, reliability, and validity advancements emanating from LIS. In fact, some readers of this editorial may be surprised to learn that there are such advancements. LIS has made a positive contribution to cross-disciplinary and interdisciplinary research relating to bibliometrics, unobtrusive testing, focus group interviewing, and in-person interviewing of ethnic-linguistic gatekeepers, ${ }^{9}$ to name a few areas. For example, Terence Crowley and Thomas Childers nudged unobtrusive testing in a new direction, ${ }^{10}$ while Charles $\mathrm{R}$. McClure and I combined unobtrusive testing with an experimental design and applied twenty-five indicators of reliability and validity to our work." McClure et al. combined focus group interviewing with a quantitative data collection technique, and included measures of reliabil- 
ity and validity. ${ }^{12}$ Based on the premise that information is culture specific, Cheryl Metoyer-Duran adapted traditional interviewer training techniques to reveal any non-English language patterns or cultural behaviors that might affect a study's reliability and validity. ${ }^{13}$

With some universities questioning the continuation of LIS schools, ${ }^{14}$ there is need for the conduct and reporting of more procedural studies and their inclusion in the published literature. LIS research-oriented journals, as well as funding organizations, ought to be supportive of such research.

What else can be done? We might:

- review research-based books produced in other professions and disciplines, noting the omission of important LIS procedural studies and coverage of the types of evaluations encountered in complex organizations, such as libraries and information centers;

- conduct procedural and other types of research with investigators from other professions and disciplines, thereby altering the self-contained paradigm noted by Gatten;

- expect more LIS faculty directing doctoral students, and the students themselves, to be well versed and experienced in the conduct of different types of research and the use of various theoretical frameworks;

- offer special awards and prizes for such research; and

- attend sessions of professional associations in which researchers present procedural studies.
However, implementation of suggestions such as these will have minimal impact as long as many librarians and library school educators demean or ignore the value of the LIS research literature and prize the literatures of other professions and disciplines more than they do their own. ${ }^{15}$ Clearly, it is imperative to attack the prevailing misperceptions about LIS literature if LIS is to mature as a profession and discipline and if we expect others to use and value our literature.

Mary Jo Lynch issued a challenge: change "the connection between research and librarianship ... from one that is uneasy to one that is firm."16 To meet the challenge, she stressed that

leaders in the field need to pay careful attention to several factors: to the numerous meanings of the word research and the different ways each kind of research affects librarianship; to educational programs that develop an ability to understand and conduct scientific research; to publications and programming that discuss work in progress and disseminate final results; to increasing the availability of funding; and, finally, to the incorporation of a research perspective into the way librarians think about what they do. ${ }^{17}$

An added challenge is to focus on the type of research that makes a procedural contribution or gains recognition for LIS in the research methods literatures of other professions and disciplines.

PETER HERNON Simmons College

\section{REFERENCES AND NOTES}

1. Jeffrey N. Gatten, "Paradigm Restrictions on Interdisciplinary Research into Librarianship," College \& Research Libraries 52:575 (Nov. 1991).

2. Ibid.

3. Ibid.

4. See Kathy B. Enger, Georgia Quirk, and J. Andrew Stewart, "Statistical Methods Used by Authors of Library and Information Science Journal Articles," Library \& Information Science Research 11:37-46 (Jan.-Mar. 1989); Danny P. Wallace, "The Use of Statistical Methods in Library and Information Science," Journal of the American Society for Information Science 36:402-10 (Nov. 1985); and Peter Hernon, Statistics: A Component of the Research Process (Norwood, N.J.: Ablex, 1991), p.72.

5. Gatten, "Paradigm Restrictions on Interdisciplinary Research into Librarianship," p.579,583.

6. Ibid., p.583 
7. Ibid.

8. Delbert C. Miller, Handbook of Research Design and Social Measurement, 5 th ed. (Newbury Park, Calif.: Sage, 1991).

9. Gatekeepers help individuals gain access to the resources needed to solve problems; they link people with solutions by serving as information providers and by moving between cultures.

10. Terence Crowley and Thomas Childers, Information Service in Public Libraries: Two Studies (Metuchen, N.J.: Scarecrow Pr., 1971).

11. See Peter Hernon and Charles R. McClure, Unobtrusive Testing and Library Reference Services (Norwood, N.J.: Ablex, 1987), chapter 4 and appendix A; and Peter Hernon and Charles R. McClure, "Quality of Data Issues in Unobtrusive Testing of Library Reference Service: Recommendations and Strategies," Library \& Information Science Research 9:77-93 (Apr.-June 1987).

12. Charles R. McClure, Ann P. Bishop, Philip Doty, and Howard Rosenbaum, The National Research and Education Network (NREN): Research and Policy Perspectives (Norwood, N.J.: Ablex, 1991).

13. Cheryl Metoyer-Duran, Information Gatekeepers in California's Ethnic Communities (Sacramento, Calif.: California State Library, 1991).

14. See, for instance, Report of the Provost on the School of Library Service at Columbia (New York: Columbia Univ., 1990): "research ..., in all library schools, is not on a level with university expectations. Even the best library schools, we are told, do not produce much research of real distinction. The lack of a national research capability in the field is widely deplored" (p.20).

15. See Peter Hernon, "Ácademic Librarians and the Library and Information Science Monograph: An Exploratory Study," College \& Research Libraries 52:507-19 (Sept. 1991).

16. Mary Jo Lynch, "Research and Librarianship: An Uneasy Connection," Library Trends 32:381 (Spring 1984).

17. Ibid.

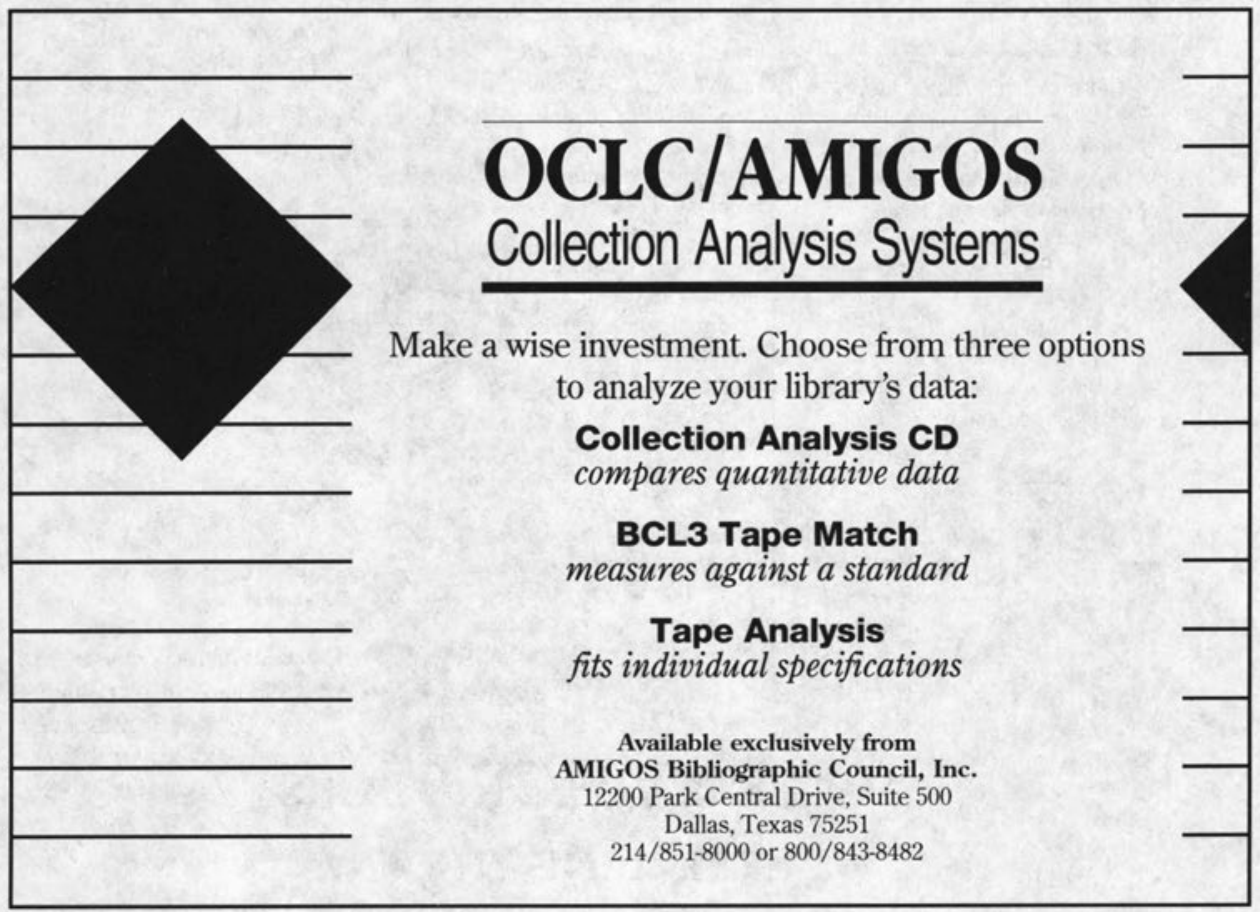




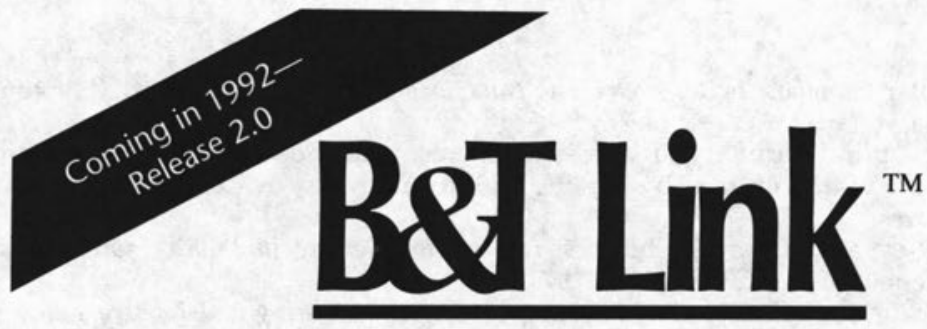

It's now even bigger, faster, and more accurate-
connecting you to our 10 million book inventory
lus any in-print, out-of-print, and forthcoming title.

Fill all your book ordering needs in one place in record time thanks to B\&T Link ${ }^{\mathrm{TM}}$ - an extraordinary system of search and order software modules from Baker \& Taylor Books. With more refinements and conveniences than you ever dreamed possible, B\&T Link literally puts any book at your fingertips.

\section{Module 1: Ordering}

Get it smarter, faster, easier. No matter how simple or intricate your ordering method, ordering through $\mathrm{B} \& \mathrm{~T}$ Link gives you lots of new advantages. Our special order feature lets you customize every line item with customer requests, multiple distribution notes, as well as print notification postcards.

Now, in addition to sending orders upon completion, you

can also transmit


orders automatically into our mainframe at a convenient predetermined time. Use our new ordering interfaces to output data in a variety of standard formats to other software products. Or check in shipments with our new on-screen receiving.

And of course, B\&T Link still provides the most comprehensive confirmation report you can get. And it's yours free.

\begin{tabular}{c} 
Module 2: \\
Database, \\
The Title Source \\
\hline
\end{tabular}

Find any book, in every detail. B\&T Link's new Module 2 bibliographic software on CD-Rom puts you in complete command of over 1.2 million book, video, audio, calendar, in-print, out-of-print and forthcoming titles. You'll enjoy extraordinary accuracy through our system of "linked" ISBN's that automatically takes you to the most recent ISBN. Nine easy ways to search our comprehensive database allow you to quickly create a title listing, including hard-to-find titles. We've even made searching up to $20 \%$ faster.
Database, The Title Source reports on everything from multiple bindings to the latest price and publication status, and is updated every month to include more than 80,000 changes.

\section{Module 3: Inventory}

Take stock at a glance. Using B\&T Link Inventory software is like standing in our warehouse. You'll know immediately what's in stock and what's on order in our service center.

$$
\text { You'll get weekly up- }
$$
dates on diskettes of an inventory with over 120,000 titles. And that's not all. Soon to be added to the B\&T Link system are Invoicing, Ordering History, Fund Accounting, and Open-to-Buy modules. When it comes to getting a book, B\&T Link is the system that does it with convenience and the Any Book advantage.

For more information, call (800) 235-4490. International customers please call (908) 218 3905.

\section{BAKER \& TAYLOR Books}

